Bull. Mater. Sci., Vol. 4, Number 1, March 1982, pp. 29-35. C Printod in Indi 1.

\title{
Fracture toughness of cast aluminium alloys
}

\author{
S RANGANATHA and MALUR N SRINIVASAN \\ Department of Mechanical Engineering, Indian Institute of Science, \\ Bangalore 560 012, India
}

MS received 27 January 1981 ; revised 9 April 1981

\begin{abstract}
An investigation was carried out to evaluate the fracture toughness of cast aluminium alloys of different microstructural complexity, brought about by alloy constitution and cooling rate of castings. In all cases the three-point bend specimens, which had a thickness of $15 \mathrm{~mm}$, did not provide valid plane - strain stress intensity factor values. The fracture susceptibility at a given stress level reckoned in terms of the conditional plane strain stress intensity factor $\left(K_{Q}\right)$ was found to be lowest in aluminium- $4.5 \%$ copper alloy castings and the susceptibility increased with increase in microstructural complexity. Casting cooling rate in these castings is likely to affect the damage potential of a given defect at yield stress to a greater extent than the fracture susceptibility at a given stress.
\end{abstract}

Keywords. Fracture toughness ; cast aluminium alloys ; fail-safe design ; microstructure: solid solution alloy; binary eutectic; ternary alloy ; particulate composite: stress intensity factor; damage potential; yield stress.

\section{Introduction}

Aluminium alloys are widely used in industrial applications where the high strength to weight ratio of these alloys is advantageous, notably in aircraft and space applications. While smooth tensile properties have been predominantly used as a basis for the selection of alloys for various applications, the need for fracture toughness data is being increasingly realised, especially for fail-safe design. Considerable amount of work has been carried out to evaluate the fracture toughness of wrought aluminium alloys by Chu (1969) and Carman et al (1965) but there is paucity of such data on cast aluminium alloys. Since the microstructure of cast aluminium alloys is affected considerably by the alloy complexity and often by the casting processing conditions there is a strong need to evaluate the effect of these variables on the fracture toughness of these alloys.

Cast aluminium alloys are available in several combinations of alloying elements, producing microstructures of different complaxity. As a first step therefore, it was decided to choose several alloys of gradually increasing 
complexity for the generation of fracture toughness data. It was felt that such data would serve as a useful guide as to the influence of microstructure on fracture behaviour and would pave way for evaluating the fracture characteristics of other aluminium alloys. Accordingly four alloys, a binary solid solution alloy, a binary eutectic, a ternary alloy and a particulate composite were chosen. Two alloys were cast at widely different cooling rates with the intention of producing different microstructures. The fracture toughness data obtained under these conditions are reported and discussed in this paper.

\section{Experimental}

In table 1 are listed the nominal chemical compositions of the alloys used. These alloys were melted in an oil-fired crucible furnace and poured into moulds after degassing with hexachloroethane and adding Al-5 $\mathrm{Ti}$ grain refiner. In the case of the particulate composite $2 \%$ by weight $\mathrm{Al}_{2} \mathrm{O}_{3}\left(100\right.$ mesh) preheated to $400^{\circ} \mathrm{C}$ was added to the melt prior to pouring. Two batches of castings were made from the melt, one in dry sand moulds and the other in cast iron moulds preheated to $150^{\circ} \mathrm{C}$ in the case of $\mathrm{Al}-4.5 \% \mathrm{Cu}$ and $\mathrm{Al}-12 \%$ silicon alloys.

Table 1. Chemical composition of alloys

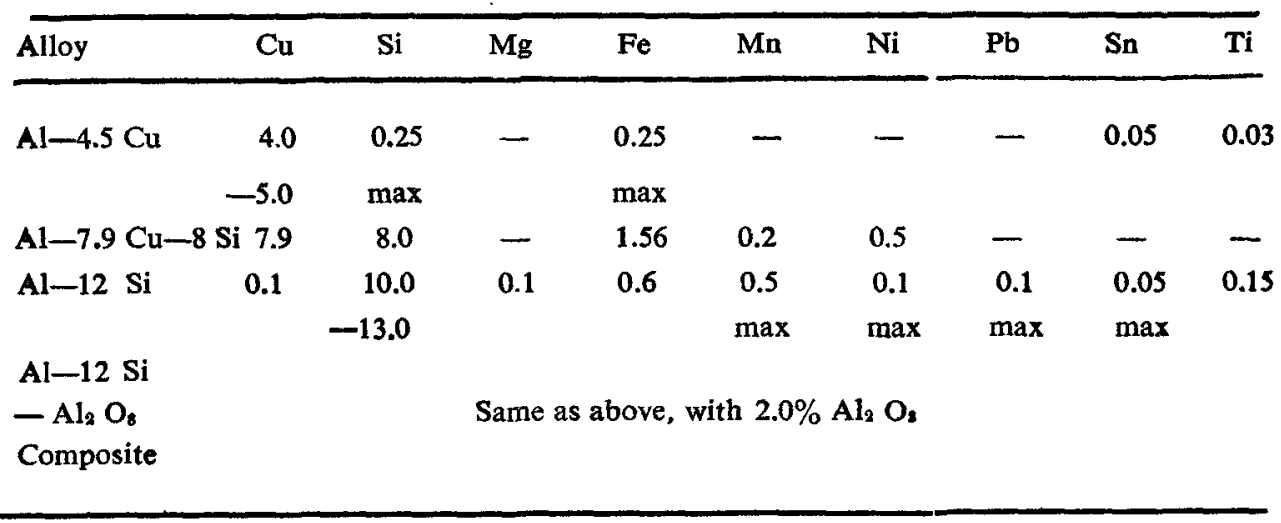

Three-point bend specimens (figure 1) prepared according to ASTM E-399-74 were machined from these castings. The thickness $B$ of these specimens was $15 \mathrm{~mm}$, the width was $30 \mathrm{~mm}$ and the length was $140 \mathrm{~mm}$. The crack length comprising the machined notch and the fatigue crack was maintained at about 0.5 times the width.

The fracture toughness tests were performed in a 50-ton MTS testing machine. A Ti-6Al clip gauge fabricated in the laboratory was used to measure the displacement, the gauge being calibrated prior to use with a strain measuring bridge. The MTS testing machine was also used to determine the smooth tensile properties of the casting. The experimental set-up is shown in figure 2 . 


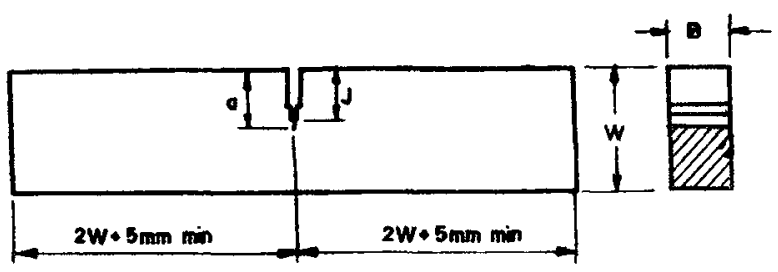

Thickness $=\theta=$ Moterial thickness

Width $=W=2 B$

Crack length $=0=0.5 \mathrm{~W}=\mathrm{B}$

Notch length $=f=(0-2.5 \mathrm{~mm})$ max for $B \geq 13 \mathrm{am}$.

Figure 1. Three-point bend specimen.

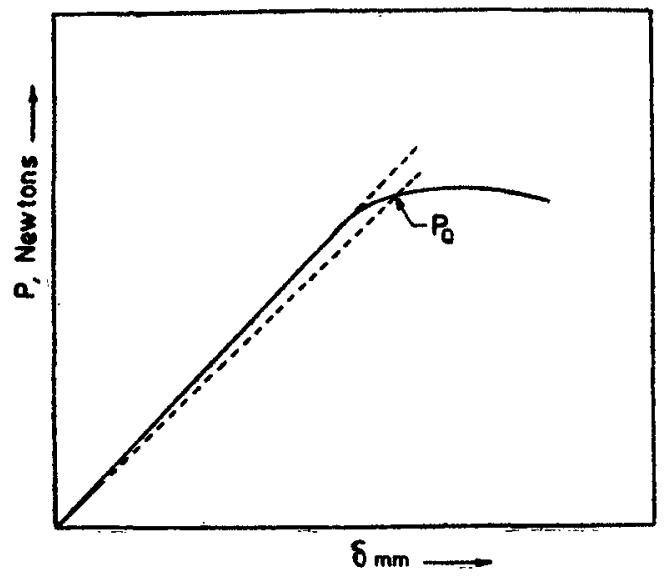

Figure 3. Typical load-displacement curve (schematic).

\section{Results and discussion}

In figure 3 is shown a typical load-displacement curve recorded in the MTS from which the conditional stress intensity factor $K_{Q}$ was evaluated using the expression (Brown 1970)

$$
K_{Q}=\frac{P_{Q} S}{B W^{3 / 2}} \quad f^{(a / w)} \quad \times 0.0348
$$

where $P_{Q}=$ load in newtons (5\% secant);B= thickness of the specimen in $\mathrm{mm}$; $S=$ span length in $\mathrm{mm} ; W=$ depth of the specimen in $\mathrm{mm} ; A=$ crack length in $\mathrm{mm}$;

$$
\begin{aligned}
f(a / w)= & {\left[2.9\left(a / w^{1 / 2}\right)-4.6(a / w)^{9 / 2}+21.8(a / w)^{5 / 2}-\right.} \\
& \left.-37.6(a / w)^{7 / 2}+38.7(a / w)^{9 / 2}\right],
\end{aligned}
$$


$K_{Q}=$ conditional stress intensity factor in $\mathrm{MN} m^{-3,2}$.

$K_{Q}$ is termed the plane-strain stress intensity factor $K_{\mathrm{IC}}$,

if $B \leqslant\left(\frac{K_{Q}}{\sigma_{y}}\right)^{2} \times 2.5$ (Brown 1970)

where $\sigma_{Y}=$ yield stress of the material in $\mathrm{MN} \mathrm{m}^{-2}$;

$K_{Q}=$ stress intensity factor in $\mathrm{MN} \mathrm{m}^{-3 / 2}$;

$B=$ thickness of the specimen in metres.

Smaller values of $B$ give rise to invalid plane-strain stress intensity factor results. In table 2 are listed the $K_{Q}$ values obtained for different castings as well as the corresponding smooth tensile properties. It may be computed from the figures in the table that the stress intensity factor values of all the castings examined are invalid plane-strain stress intensity factor values. Therefore $K_{I C}$ values required for design purposes should be obtained from additional knowledge about stress intensity factor values at other thickness, or on the basis of elastoplastic fracture mechanics analysis (Knott 1973). Nevertheless the $K_{Q}$ values obtained may be utilized to get a qualitative understanding of the effect of alloy complexity and processing conditions upon the relative fracture susceptibility in these alloys.

When the $K_{Q}$ values are compared with the microstructures of corresponding castings shown in figures $4-8$, it becomes readily apparent that the fracture susceptibility at a given stress level in these alloys increases with increasing complexity of the microstructure. For instance, aluminium- $4.5 \%$ copper alloy displaying smallemounts of non-equilibrium eutectic in a matrix of solid solution of copper in aluminium (figure 5) has considerably higher $K_{Q}$ value compared to aluminium-7.9\% copper -8 percent silicon alloy which shows a dispersion of primary silicon and eutectic $\mathrm{Si}$ in an aluminium-rich matrix (figure 8). It is also evident that despite some difference in the microstructure, the fracture susceptibility is not appreciably affected when the casting cooling rate in a given alloy is changed from a high to a low value (figure 4-7). Further the dispersion $\mathrm{Al}_{2} \mathrm{O}_{3}$ in aluminium-12\% silicon alloy does not bring about appreciable change in $K_{Q}$ value.

In table 2 are also listed the values of the factor $\left(K_{Q} / \sigma_{y}\right)^{2}$ for the different castings examined. Based upon the assumption that $K_{Q}$ values may be utilized to provide an understanding of the relative fracture toughness of the different castings, the $\left(K_{Q} / \sigma_{y}\right)^{2}$ values may be considered to be representative of the relative damage potential of a given defect at yield stress in these castings. A study of table 2 indicates that the damage potential of a given defect at yield stress is likely to be greater when the casting is made in a metal mould, than when it is made in a sand mould. Further, the dispersion of insoluble, hard particles is likely to increase significantly the damage potential of a given defect at yield stress in aluminium- $12 \%$ silicon alloys castings. The absolute values of critical flaw sizes of different geometries should of course be computed from $K_{1 \mathrm{C}}$ values, which could be determined as indicated earlier. 

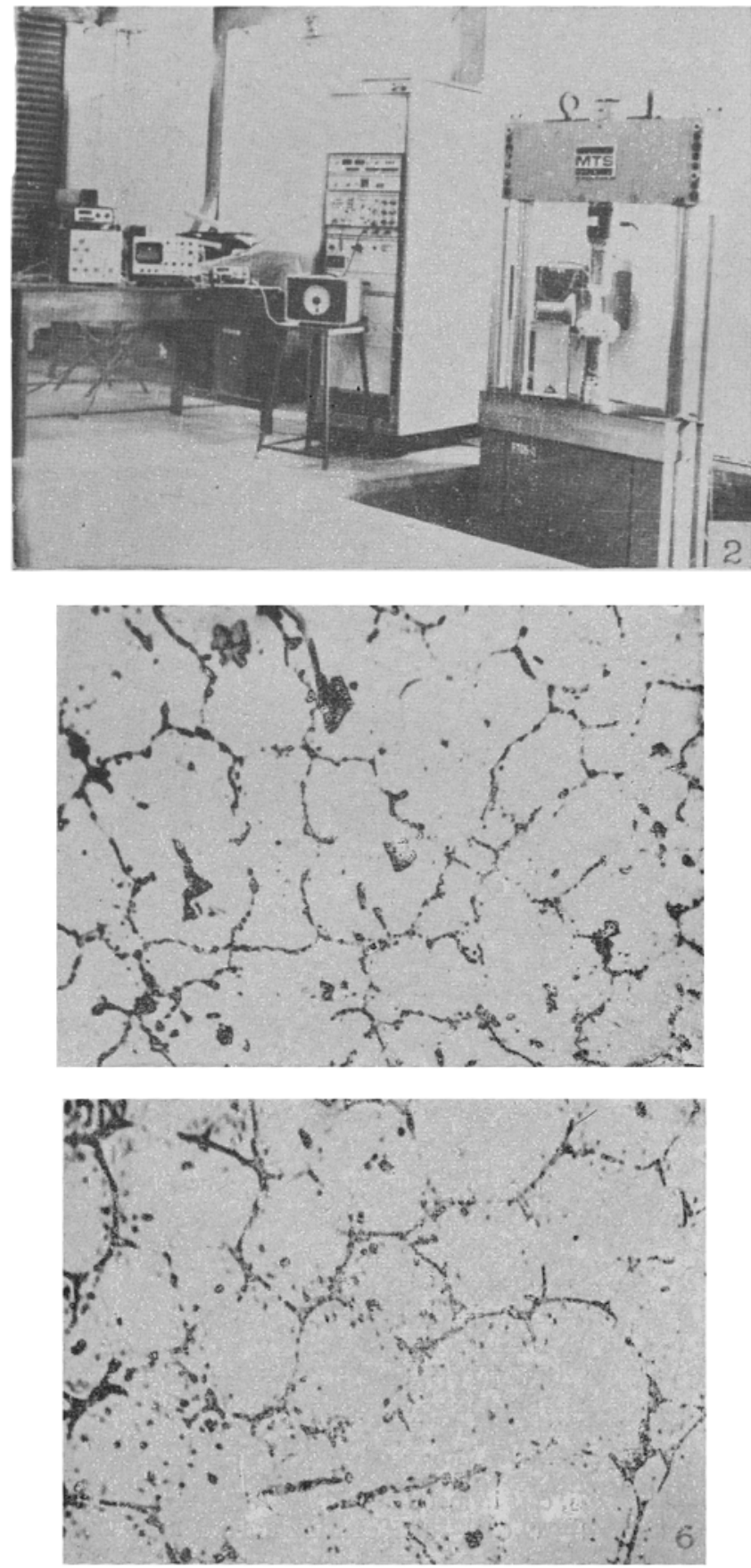

Figure 2-4-5 . 2 Experimental set up, 4. $\mathrm{Al}-4.5 \mathrm{Cu}$, cast in metal mould,

5. Al-4.5 Cu, cast in sand mould. 

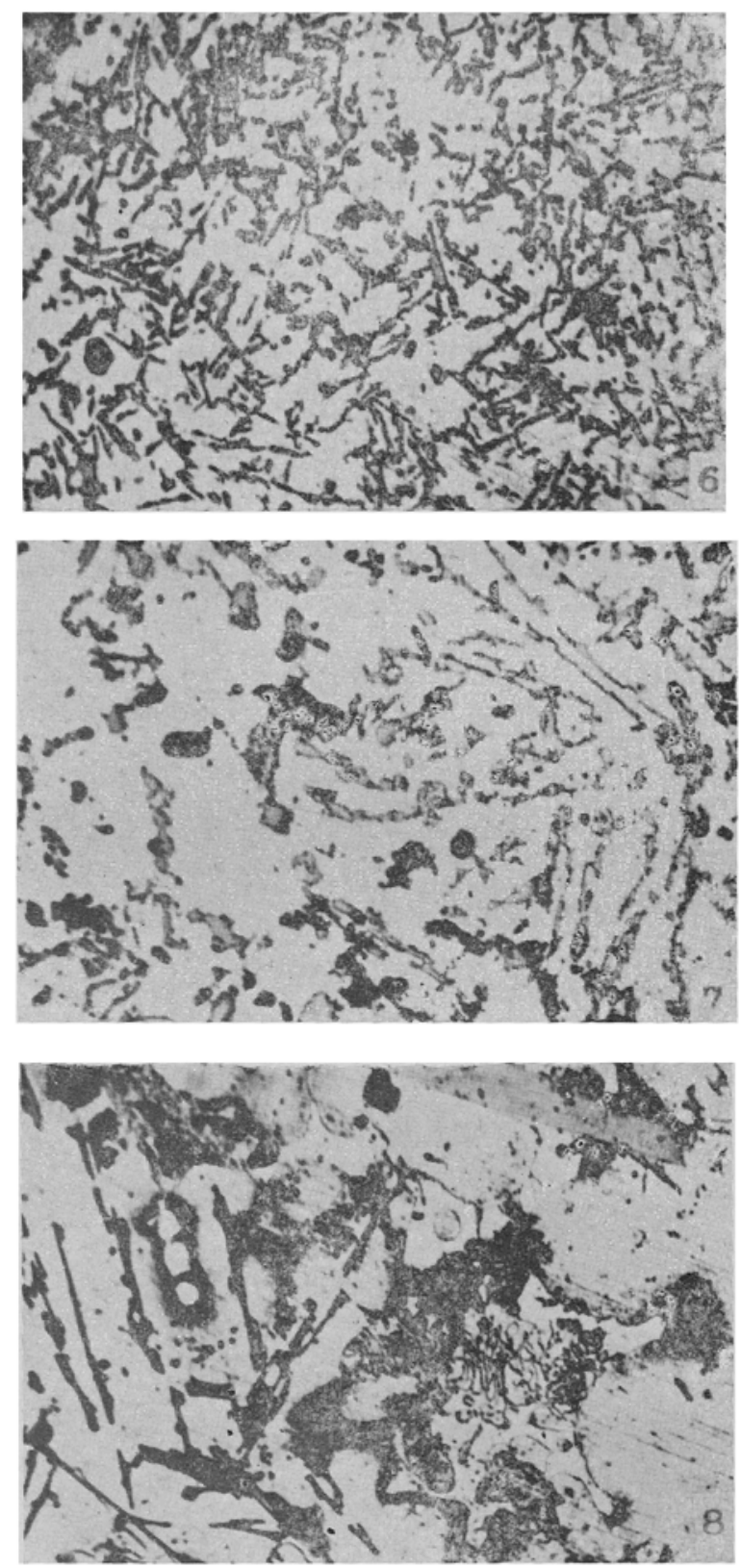

Figure 6-8 6. Al-12 Si, cast in metal mould, 7. Al-12 Si, cast in sand mould, 8. Al-7.9 $\mathrm{Cu}-8 \mathrm{Si}$, cast in sand mould. 
Table 2. Fracture susceptibility data

\begin{tabular}{lccc}
\hline Alloys & Mould & MN $m_{-3: 2}$ & $\left(K_{Q} / \sigma_{y}\right)^{2}$ \\
\hline $\mathrm{Al}-4.5 \mathrm{Cu}$ & Metal & 16.49 & 0.084 \\
& Sand & 15.73 & 0.108 \\
$\mathrm{~A} 1-12 \mathrm{Si}$ & Metal & 12.10 & 0.068 \\
& Sand & 12.67 & 0.111 \\
$\mathrm{Al}-7.9 \mathrm{Cu}-8 \mathrm{Si}$ & Sand & 9.98 & 0.094 \\
$\mathrm{Al}-12 \mathrm{Si}$ & Metal & 13.09 & 0.037 \\
$-2 \mathrm{Al}_{2} \mathrm{O}_{2}$ & & & \\
\hline
\end{tabular}

\section{Conclusions}

Among the castings examined in this paper the fracture susceptibility at a given stress is lowest in aluminium-4.5\% copper alloy castings; the fracture susceptibility progressively increases as the alloy is changed to aluminium- $12 \%$ silicon and then to aluminium-7.9\% copper-8\% silicon, wherein the microstructures also become progressively more complex, in that order. Casting cooling rate in these castings appears to have a more significant effect upon the damage potential of a given defect at yield stress, than upon the fracture susceptibility at a given stress.

\section{Acknowledgements}

The authors would like to thank Mr S Seetharamu for invaluable help at various stages. They would also like to thank Prof. A K Rao and Dr B Dattaguru of the Department of Aeronautical Engineering, Indian Institute of Science, for providing the MTS testing machine for this work.

\section{References}

Brown W F Jr 1970 Review of developments in plane-strain fracture toughness ASTM STP 463161

Carman C M, Armiento D F and Markus H 1965 J. Basic Engg. Trans. ASME D87 904

Chu H P 1969 J. Basic Engg. Trans. ASME D 91830

Knott J F 1973 Fundamentals of fracture mechanics (London Butterworths) 150 